\title{
Особенности правового регулирования
} общественного контроля

\section{в Российской Федерации на федеральном, региональном и муниципальном уровнях (конституционно-правовой анализ)}

\author{
КЛЮЧЕВЫЕ СЛОВА: \\ Федеральное, региональное, муниципальное законодательство, \\ общественный контроль, Российская Федерация, \\ конституционно-правовой анализ, народ, участие в управлении \\ государственными делами, власть
}

Национальное российское законодательство, составляющее основу конституционно-правовой организации механизма общественного контроля в России, представлено Конституцией Российской Федерации; федеральным законодательством (федеральными конституционными законами, федеральными законами, актами Президента и Правительства страны, федеральных министерств и ведомств); региональным законодательством (конституциями и уставами субъектов Российской Федерации, региональными законами и подзаконными актами); муниципальным законодательством (уставами муниципальных образований и муниципальными нормативно-правовыми актами).

При этом, в рамках федерального, регионального и муниципального законодательства, нормативно-правовые акты, условно, можно классифицировать на следующие подгруппы: 1) регулирующие правовой статус федеральных, региональных и местных органов власти; 2) регулирующие вопросы общественного контроля при формировании органов публичной власти всех уровней; 3) регулирующие вопросы общественного контроля в целом; 4) регулирующие вопросы отдельных аспектов общественного контроля власти (например, экологический общественный контроль, общественный контроль за местами лишения свободы); 5) регулирующие вопросы уча- 
стия некоммерческих организаций в общественном контроле (в частности, профсоюзных, природоохранных); 6) регулирующие вопросы общественного контроля за органами и организациями, осуществляющими полномочия, делегированные органами публичной власти в соответствии с действующим законодательством.

Конституция Российской Федерации не содержит определения понятия общественного контроля, но установила, в частности, что: носителем суверенитета и единственным источником власти в Российской Федерации является ее многонациональный народ, который осуществляет ее непосредственно, а также через органы государственной власти и местного самоуправления (ч. 1 и 2 статьи 3); в Российской Федерации признается идеологическое разнообразие (ч. 1 статьи 13); граждане России вправе объединяться и создавать общественные объединения как разновидность юридических лиц (ч. 4 статьи 13); граждане страны имеют право участвовать в управлении делами государства как непосредственно, так и через своих представителей (статья 32) и обращаться лично, а также направлять индивидуальные и коллективные обращения в государственные органы и органы местного самоуправления (статья 33) ${ }^{1}$.

При этом, право народа на осуществление народовластия и участие в управлении государственными делами основной закон страны ничем не ограничивает, в то время как посягательства любых органов власти и их должностных лиц на принадлежащую народу власть, делегируемую избираемым органам государственной власти и местного самоуправления, преследуются по закону, вплоть до привлечения к уголовной ответственности.

В числе нормативно-правовых актов, регулирующих правовой статус федеральных, региональных и местных органов власти, можно выделить, например, Федеральный конституционный закон «О Правительстве Российской Федерации» от 17.12.1997 № 2-ФК3, который не содержит детального правового регулирования общественного контроля в стране, но в главе 6 закрепляет формы государственного (внутреннего) контроля за деятельностью Правительства России:

1) доверие, недоверие и отказ в доверии Правительству Российской Федерации;

2) ответы членов Правительства Российской Федерации на вопросы членов Совета Федерации и депутатов Государственной Думы;

3) ответы на запросы членов Совета Федерации и депутатов Государственной Думы;

1 См.: Конституция Российской Федерации (принята всенародным голосованием 12.12.1993), «Российская газета» 19.12.1993, № 273. 
4) ответы на письменные обращения комитетов и комиссий палат Федерального Собрания;

5) ежегодные отчеты Правительства Российской Федерации о результатах его деятельности, в том числе по вопросам, поставленным Государственной Думой;

6) предоставление информации об исполнении федерального бюджета 2 .

Таким образом, предусмотренный данным федеральным конституционным законом контроль высшего органа исполнительной власти в стране со стороны палат федерального парламента (Государственной Думы, избираемой населением и Совета Федерации, формируемого избираемыми органами власти субъектов Российской Федерации), позволяет народу осуществлять опосредованный общественный контроль данной ветви власти.

Федеральный закон «О статусе члена Совета Федерации и статусе депутата Государственной Думы Федерального Собрания Российской Федерации» от 08.05.1994 № 3-Ф3, в свою очередь, закрепляет ряд норм, закрепляющих отдельные формы контроля народа за федеральным парламентом России, например, обязывающих депутатов Государственной Думы и членов Совета Федерации отчитываться перед избирателями (народом). В частности, в части 2 статьи 8 предусмотрена обязанность депутатов по рассмотрению обращений избирателей и личному приему граждан, а в части 3 статьи 8 - по информированию избирателей о своей деятельности во время встреч с ними, а также через средства массовой информации 3 .

Это позволяет Федеральному Собранию Российской Федерации, с одной стороны, отчитываться перед избирателями в постоянном режиме, а с другой стороны, получать своевременную информацию о положении дел в стране в части соблюдения, охраны, защиты и исполнения прав, свобод и законных интересов человека и гражданина.

В связи с тем, то федеральный парламент России (его нижняя палата) непосредственно избирается населением и состоит из его представителей, представляет интерес право депутатов по контролю власти: парламентский запрос (статья 13); депутатский запрос (статья 14); приглашение членов Правительства Российской Федерации и других должностных лиц на заседание соответствующей палаты Федерального Собрания Российской Федерации (статья 15); право члена Совета Федерации, депутата Государственной Думы на прием в первоочередном порядке руководителями и другими

2 См.: О Правительстве Российской Федерации: Федеральный конституционный закон от 17.12.1997 № 2-ФКЗ, СЗ РФ. 22.12.1997, № 51, Ст. 5712.

3 См.: О статусе члена Совета Федерации и статусе депутата Государственной Думы Федерального Собрания Российской Федерации: Федеральный закон от 08.05.1994 № 3-Ф3, С3 РФ. 12.07.1999, № 28, Ст. 3466. 
должностными лицами (статья 16); право члена Совета Федерации, депутата Государственной Думы на получение и распространение информации (статья 17) ${ }^{4}$.

Эти формы контроля властного механизма со стороны Федерального парламента (при этом, наполненные реальными полномочиями) существенно дополняют систему общественного контроля в стране.

В свою очередь, Федеральный конституционный закон от 31.12.1996 № 1-ФКЗ «О судебной системе Российской Федерации», закрепляет формы участия народа в отправлении правосудия, а также его контроля за органами судебной власти. Например, в статье 8 предусматривается возможность участия граждан Российской Федерации в осуществлении правосудия в порядке, предусмотренном федеральным законом, в том числе и в виде присяжных и арбитражных заседателей, а в статье 9 - гласность в деятельности судов ${ }^{5}$.

Данные нормы существенно минимизируют коррупционную составляющую в организации и деятельности органов судебной власти и позволяют обществу в режиме реального времени реагировать на избрание мер уголовной ответственности по наиболее тяжким преступлениям, предусмотренным Уголовным кодексом Российской Федерации.

Федеральный закон «Об общих принципах организации законодательных (представительных) и исполнительных органов государственной власти субъектов Российской Федерации» от 06.10.1999 № 184-Ф3, в свою очередь, предусматривает в статье 3.1 ответственность органов государственной власти субъектов Российской Федерации в случае принятия нормативных правовых актов, противоречащих действующему законодательству и повлекших за собой массовые и грубые нарушения прав и свобод человека и гражданина ${ }^{6}$. Данная форма политической ответственности региональных органов государственной власти выступает в роли дополнительной гарантии права народа на осуществление общественного контроля власти.

В свою очередь, Федеральный закон «Об общих принципах организации местного самоуправления в Российской Федерации» от 06.10.2003 № 131-Ф3 в ряде своих статей предусматривает обширные права граждан России на осуществление местного самоуправления и контроль за его органами: возможность проведения местного референдума (статья 22); голосование по

4 См.: Там же.

5 См.: О судебной системе Российской Федерации: Федеральный конституционный закон от 31.12.1996 № 1-ФКЗ «О судебной системе Российской Федерации», СЗ РФ. 06.01.1997, № 1, Ст. 1 .

6 См.: Об общих принципах организации законодательных (представительных) и исполнительных органов государственной власти субъектов Российской Федерации: Федеральный закон от 06.10.1999 № 184-Ф3, С3 РФ. 18.10.1999, № 42, Ст. 5005. 
отзыву депутата, члена выборного органа местного самоуправления, выборного должностного лица местного самоуправления, голосование по вопросам изменения границ муниципального образования, преобразования муниципального образования (статья 24); возможность проведения схода граждан, осуществляющего полномочия представительного органа муниципального образования (статья 25); правотворческую инициативу граждан (статья 26); публичные слушания, общественные обсуждения (статья 28); собрание граждан (статья 29); конференцию граждан (собрание делегатов) (статья 30); обращение граждан в органы местного самоуправления (статья 32); другие формы непосредственного осуществления населением местного самоуправления и участия в его осуществлении (статья 33)7.

Таким образом, следует отметить, что федеральное законодательство, регулирующее вопросы местного самоуправления, содержит более репрезентативные формы прямого общественного контроля за органами местного самоуправления и их должностными лицами, по сравнению с аналогичным контролем федеральных и региональных органов государственной власти.

В числе нормативно-правовых актов, регулирующих вопросы общественного контроля при формировании органов власти, следует выделить, например, федеральные законы «О выборах Президента Российской Федерации» от 10.01.2003 № 19-Ф3, «О выборах депутатов Государственной Думы Федерального Собрания Российской Федерации» от 22.02.2014 № 20-Ф3, предусмотревшие участие в избирательной кампании общественных наблюдателей и наблюдателей от политических партий ${ }^{8}$. Аналогичные формы участия граждан в избирательном процессе предусмотрены на региональном и муниципальном уровнях ${ }^{9}$. Кроме того, представители политических партий и общественных движений входят в состав избирательных комиссий всех уровней (от участковых до Центральной избирательной комиссии Российской Федерации) в качестве их членов с совещательным и решающим голосом.

7 См.: Об общих принципах организации местного самоуправления в Российской Федерации: Федеральный закон от 06.10.2003 № 131-Ф3, С3 РФ. 06.10.2003, № 40, Ст. 3822.

8 См.: О выборах Президента Российской Федерации: Федеральный закон от 10.01.2003 № 19-Ф3, С3 РФ. 13.01.2003, № 2, Ст. 171; О выборах депутатов Государственной Думы Федерального Собрания Российской Федерации: Федеральный закон от 22.02.2014 № 20-Ф3, С3 РФ. 24.02.2014, № 8, Ст. 740.

9 См. подробнее, например: О выборах главы администрации (губернатора) Краснодарского края: Закон Краснодарского края от 03.07.2012 № 2519-КЗ, «Кубанские новости» 08.07.2012, № 126; О муниципальных выборах в Краснодарском крае: Закон Краснодарского края от 26.12.2005 № 966-КЗ [Электронный ресурс]. Режим доступа: http://docs.cntd.ru/document/461608554 (дата обращения: 01.11.2018). 
Участие представителей общественности в избирательном процессе на всех его уровнях позволяет, во-первых, обеспечить законность при проведении выборов и референдумов, минимизировав фальсификации их результатов, во-вторых, осуществлять постоянный общественный контроль за ходом избирательной кампании и кампании по проведению референдума, в-третьих, оперативно информировать общество через средства массовой информации, а также деятельность общественных организаций и движений (включая политические партии) о любых нарушениях политических прав граждан.

В числе нормативно-правовых актов, регулирующих общие вопросы общественного контроля в России, следует выделить федеральные законы «Об основах общественного контроля в Российской Федерации» от 21.07.2014 № 212-Ф310, «Об Общественной палате Российской Федерации» от 04.04.2005 № 32-Ф311, которые содержат наиболее полную правовую регламентацию системы общественного контроля в Российской Федерации.

Они создают в соответствии со статьями 71 и 72 Конституции Российской Федерации, с одной стороны, правовую основу для осуществления общественного контроля в нашей стране на федеральном уровне, а с другой стороны, определяют пределы правового регулирования общественного контроля нормативно-правовыми актами на уровне регионов и муниципальных образований.

На уровне субъекта Российской Федерации (например, Краснодарского края) вопросы общественного контроля урегулированы законами Краснодарского края от 25.12.2015 № 3305-К3 «Об общественном контроле в Краснодарском крае»12, от 03.03.2017 № 3575-К3 «Об Общественной палате Краснодарского края и о внесении изменений в отдельные законодательные акты Краснодарского края» ${ }^{13}$. Данные нормативно-правовые акты приняты на основании федерального законодательства и посвящены формированию и функционированию системы общественного контроля на уровне региона.

Так, Закон Краснодарского края от 25.12.2015 № 3305-К3 «Об общественном контроле в Краснодарском крае» закрепляет систему субъектов

10 См.: Об основах общественного контроля в Российской Федерации: Федеральный закон от 21.07.2014 № 212-Ф3, «Российская газета» 23.07.2014, № 6435 (163).

11 См.: Об Общественной палате Российской Федерации: Федеральный закон от 04.04.2005 № 212-Ф3, С3 РФ. 11.04.2005, № 15, Ст. 1277.

12 См. Об общественном контроле в Краснодарском крае: Закон Краснодарского края от 25.12.2015 № 3305-К3 [Электронный ресурс]. Режим доступа: http://www.garant. ru/hotlaw/krasnodar/690617 (дата обращения: 01.11.2018).

13 См.: Об Общественной палате Краснодарского края и о внесении изменений в отдельные законодательные акты Краснодарского края: Закон Краснодарского края от 03.03.2017 № 3575-К3 [Электронный ресурс]. Режим доступа: http://admkrai. krasnodar.ru (дата обращения: 01.11.2018). 
общественного контроля на территории Краснодарского края (в которую входят, в частности, Общественная палата Краснодарского края, общественные советы при Законодательном Собрании Краснодарского края, при исполнительных органах государственной власти Краснодарского края и органах местного самоуправления в Краснодарском крае, общественные инспекции и группы общественного контроля), определяет их полномочия, а также формы и результаты общественного контроля (общественные проверки, экспертизы, обсуждения $)^{14}$.

Важное значение в организации общественного контроля власти на уровне субъектов Российской Федерации играют общественные советы при региональных органах исполнительной власти (далее также - РОИВ). Так, Е. Г. Дьякова отмечает, что анализ положений об РОИВ в Уральском федеральном округе на 01.04.2016 показал, что основной акцент в них делался на: «обеспечении и оптимизации взаимодействия с гражданским обществом, общественными объединениями/гражданами (такие пункты имеются в положениях 66,6\% общественных советов); экспертизе общественно-значимых нормативно-правовых актов (51,9\%); информировании граждан о деятельности органов власти, при которых создан общественный совет $(45,5 \%)$; выдвижении, обсуждении, обобщении и поддержке гражданских инициатив (31,4\%); повышении открытости и прозрачности деятельности РОИВ $(21,7 \%)\rangle^{15}$. Таким образом, на уровне регионов процессы организации и осуществления общественного контроля предполагают широкое задействование институтов гражданского общества, включая общественные и религиозные организации и движения, а также политические партии.

На уровне муниципальных образований вопросам общего регулирования общественного контроля власти посвящены муниципальные нормативноправовые акты. Например, постановление администрации муниципального образования город Краснодар от 18.08.2010 № 6214 «Об Общественной палате муниципального образования город Краснодар» определяет Общественную палату муниципального образования город Краснодар в качестве формы участия населения в местном самоуправлении, обеспечивающей регулярное и конструктивное взаимодействие граждан, общественных объединений, некоммерческих организаций и органов местного самоуправления муниципального образования город Краснодар в решении наиболее важных

14 См. Об общественном контроле в Краснодарском крае: Закон Краснодарского края от 25.12.2015 № 3305-К3 [Электронный ресурс]. Режим доступа: http://www.garant. ru/hotlaw/krasnodar/690617 (дата обращения: 01.11.2018).

15 Е. Г. Дьякова, Общественные советь при органах исполнительной власти субъектов Федераиии: как выполняется функция общественного контроля, «Дискурс-Пи» 2016, № 2, c. 30-31. 
вопросов экономического и социального развития города, защите прав и свобод граждан, в нем проживающих ${ }^{16}$. При этом, Общественная палата муниципального образования город Краснодар играет и роль информационной площадки, на которой могут быть озвучены результаты мероприятий, проводимых в рамках общественного контроля иными субъектами общественного контроля.

Как справедливо отмечает ряд авторов: «Закон об основах общественного контроля установил систему общественного контроля в России по уровням власти (федеральный, региональный, муниципальный) и отраслевому признаку. Первый вид осуществляется общественными палатами по территориальному признаку, а второй - общественными советами при конкретном органе власти. Однако законодатель фактически создал ситуацию, при которой сегодня во многих муниципальных образованиях не существует механизмов для организации общественного контроля» ${ }^{17}$. Исправление данной ситуации требует доработки федерального законодательства в части закрепления обязанности муниципальных образований по созданию на территории муниципалитетов системы общественного контроля.

Это обстоятельство поддерживает, в частности, Д. С. Михеев, которий отмечает, что «правовая природа местного самоуправления как формы осуществления власти народом диктует требование о создании системы открытого независимого общественного контроля, который должен осуществляться населением, гражданами, общественными объединениями, не находящимися в отношениях подчинения с органами местного самоуправления... посредством чего ... можно достигнуть наибольшей открытости и гласности в работе органов местного самоуправления. Он способен не только представить объективную картину деятельности местной власти, но и вовлечь в механизм проведения общественного контроля население, повысить его информированность о вопросах, решаемых органами местного самоуправления» ${ }^{18}$.

Однако, эффективность системы общественного контроля на муниципальном уровне осложняется тем, что во многих муниципальных образо-

16 См.: Об Общественной палате муниципального образования город Краснодар: Постановление администрации муниципального образования город Краснодар от 18.08.2010 № 6214 [Электронный ресурс]. Режим доступа: http://docs.cntd.ru/document/446219111 (дата обращения: 01.11.2018).

17 См.: Т. Н. Михеева, Е. И. Белоусов, Общественный контроль на муниципальном уровне: анализ новелл законодательства, « HYPERLINK "https://elibrary.ru/contents. asp?id=34074890” Актуальные проблемы экономики и права» 2015, № 2, с. 180.

18 См.: Д. С. Михеев, Обеспечение общественного контроля - ключевое направление в развитии принципа гласности местного самоуправления, «Lex Russica» 2015, T. 101 , № 4, c. 31 . 
ваниях, как правило, отсутствуют нормативно-правовые акты, посвящённые общему правовому регулированию системы общественного контроля. Анализ нормативно-правовой базы на уровне муниципальных образований в Южном и Северо-Кавказском федеральных округах показал на 01.01.2018, что в более $80 \%$ муниципальных образований общественные палаты отсутствуют $^{19}$. Это свидетельствует о том, что, с одной стороны, региональные органы государственной власти не стимулируют создание органов общественного контроля на уровне муниципальных образований, а с другой стороны, об отсутствии денежных средств в муниципальных бюджетах, которые, как правило, носят дотационный характер, на финансирование и поддержку данных субъектов общественного контроля.

В числе нормативно-правовых актов, регулирующих вопросы отдельных аспектов общественного контроля власти в Российской Федерации (например, экологического общественного контроля, общественного контроля за местами лишения свободы), можно выделить, в частности: Федеральный закон «Об охране окружающей среды» от 10.01.2002 № 7-Ф3 (предусмотревший в статье 68 общественный контроль в области охраны окружающей среды (общественный экологический контроль); Федеральный закон «Об общественном контроле за обеспечением прав человека в местах принудительного содержания и о содействии лицам, находящимся в местах принудительного содержания» от 10.06.2008 № 76-Ф3, регулирующий механизм контроля общества над местами лишения свободы и принудительного содержания.

Так, Федеральный закон «Об охране окружающей среды» от 10.01.2002 № 7-Ф3 предусмотрел возможность граждан Российской Федерации индивидуально, либо путем участия в создании и деятельности общественных объединений, осуществлять общественный контроль за деятельностью органов государственной власти и местного самоуправления в области охраны окружающей среды (например, путем выдвижения предложения о проведении общественной экологической экспертизы и участия в ее проведении в установленном порядке; обращения в органы власти и иные организации с жалобами, заявлениями и предложениями по вопросам, касающимся охраны окружающей среды, негативного воздействия на окружающую среду, с получением своевременных и обоснованных ответов; предъявления в суд исков о возмещении вреда окружающей среде и т.п.) $)^{20}$.

19 См. подробнее: А. С. Батаев, Организация общественного контроля в Российской Федерачии на уровне мунищипальньхх образований (на примере Южного и СевероКавказского федеральных округов), Грозный 2018, с. 30-31.

20 См.: Об охране окружающей среды: Федеральный закон от 10.01.2002 № 7-Ф3, С3 РФ. 14.01.2002, № 2, Ст. 133. 
При этом, общественные объединения в целях защиты окружающей среды, осуществляющие общественный контроль, имеют возможность использовать, помимо традиционных его форм, свое право на организацию собраний, митингов, демонстраций, шествий и пикетирований с целью принудить органы публичной власти, а также иные юридические лица, к соблюдению законодательства об охране окружающей среды.

Кроме того, анализ судебной практики, проведённый рядом авторов, показывает возрастающую роль общественных объединений и организаций, осуществляющих общественный контроль, в инициировании судебного разбирательства по рассмотрению вопросов нарушения природоохранного и экологического законодательства, осуществляемого как органами государственной власти и местного самоуправления, так и частными хозяйствующими субъектами ${ }^{21}$.

В свою очередь, Федеральный закон «Об общественном контроле за обеспечением прав человека в местах принудительного содержания и о содействии лицам, находящимся в местах принудительного содержания» от 10.06.2008 № 76-Ф3 предусмотрел создание общественных наблюдательных комиссий как субъектов общественного контроля в области обеспечения прав человека в местах принудительного содержания, а также закрепил достаточно обширный перечень форм общественного контроля (посещение мест принудительного содержания; рассмотрение предложений, заявлений и жалоб лиц, находящихся в местах принудительного содержания, а также иных лиц; подготовку решений по результатам проведения общественного контроля; направление материалов по итогам осуществления общественного контроля в уполномоченные органы государственной власти и местного самоуправления, их должностным лицам, а также в вышестоящие органы общественного контроля; взаимодействие с органами публичной власти, а также иными организациями, включая участие в работе комиссий исправительных учреждений; проведение мероприятий (общественных обсуждений, слушаний) по вопросам своей деятельности) 22 .

Представляется, что данный федеральный закон является удачной формой правового регулирования организации общественного контроля в отдельных

21 См. подробнее, например: О.В. Воронцова, Общественный экологический контроль: отдельные вопросы судебной практики, «Вестник Коми республиканской академии государственной службы и управления. Серия: Государство и право» 2016, № 21, c. $103-109$.

22 См.: Об общественном контроле за обеспечением прав человека в местах принудительного содержания и о содействии лицам, находящимся в местах принудительного содержания: Федеральный закон от 10.06.2008 № 76-ФЗ, С3 РФ. 16.06.2008, № 4, Ст. 2789. 
отраслях государственного управления, и положительный опыт его работы может быть использован и в других отраслях государственного управления.

На уровне субъекта Российской Федерации (например, Краснодарского края) отдельным аспектам общественного контроля власти посвящены законы Краснодарского края от 07.12.2010 № 2124-К3 «Об экологическом мониторинге на территории Краснодарского края», от 23.07.2003 № 608-К3 «Об административных правонарушениях» ${ }^{23}$.

Так, закон Краснодарского края от 07.12.2010 № 2124-К3 «Об экологическом мониторинге на территории Краснодарского края» предусмотрел право граждан и их объединений на осуществление общественного контроля в области экологического мониторинга, в том числе возможность получать экологическую информацию, а также информацию о проводимых мероприятиях в области экологического мониторинга на территории Краснодарского края, вносить предложения в орган исполнительной власти Краснодарского края, уполномоченный в области экологического мониторинга, об организации и осуществлении экологического мониторинга на территории Краснодарского края; оказывать содействие в организации и осуществлении экологического мониторинга ${ }^{24}$. Данный региональный закон убедительно доказывает возможность организации и осуществления общественного контроля в отдельных сферах государственного управления на уровне субъектов Российской Федерации путем объединения усилий общественных организаций и объединений, отдельных граждан для проведения мероприятий общественного контроля.

В числе нормативно-правовых актов, регулирующих вопросы участия некоммерческих организаций в общественном контроле (профсоюзных, природоохранных) можно выделить: Федеральный закон «О профессиональных союзах, их правах и гарантиях деятельности» от 12.01.1996 № 10-Ф3; Федеральный закон «Об охране окружающей среды» от 10.01.2002 № 7-Ф3; Федеральный закон «О политических партиях» от 11.07.2001 № 95-Ф3.

Так, Федеральный закон «О профессиональных союзах, их правах и гарантиях деятельности» от 12.01.1996 № 10-Ф3 закрепляет достаточно широкую систему прав профессиональных союзов на осуществление общественного контроля за соблюдением прав, свобод и законных интересов работников (например, на представительство и защиту социально-трудовых прав и интересов работников; на осуществление профсоюзного контроля за соблюдением законодательства о труде; на защиту интересов работников в органах по рас-

23 См.: Об административных правонарушениях: Закон Краснодарского края от 23.07.2003 № 608-К3, «Кубанские новости» 29.07.2003, № 125.

24 См.: Об экологическом мониторинге на территории Краснодарского края: Закон Краснодарского края от 07.12.2010 № 2124-КЗ, «Кубанские новости» 13.12.2010, № 218. 
смотрению трудовых споров), а также деятельностью любых работодателей 25. При этом, законодатель гарантирует права профсоюзов на осуществление деятельности по общественному контролю за рядом обязанностей работодателей по созданию условий для осуществления деятельности профсоюзов.

В свою очередь, Федеральный закон «О политических партиях» от 11.07.2001 № 95-Ф3 предоставляет широкие полномочия политическим партиям в России по осуществлению широкомасштабного общественного контроля, в том числе, путем: участия в выработке решений органов государственной власти и органов местного самоуправления; участия в выборах и референдумах; использования государственных и муниципальных средств массовой информации, в том числе и на безвозмездной основе; свободного распространения информации о своей деятельности и т.д. ${ }^{26}$ При этом, политические партии в соответствии с действующим законодательством выведены из числа объектов общественного контроля, но обладают значительными возможностями (а парламентские партии - в том числе и финансовыми средствами) для поддержки субъектов общественного контроля любого уровня.

В числе нормативно-правовых актов, регулирующих вопросы общественного контроля за юридическими и физическими лицами, осуществляющими полномочия, делегированные органами публичной власти в соответствии с действующим законодательством, можно выделить, например: Федеральный закон от 03.12.2011 № 392-Ф3 «О зонах территориального развития в Российской Федерации и о внесении изменений в отдельные законодательные акты Российской Федерации», Федеральный закон от 29.12.2014 № 473-Ф3 «О территориях опережающего социально-экономического развития в Российской Федерации».

Например, Федеральный закон от 29.12.2014 № 473-Ф3 «О территориях опережающего социально-экономического развития в Российской Федерации» предусмотрел обязанность по включению в состав наблюдательного совета территории опережающего социально-экономического развития представителей территориальных объединений (ассоциаций) организаций профсоюзов для осуществления общественного контроля за соблюдением резидентами территории опережающего социально-экономического развития действующего законодательства, а также прав, свобод и законных интересов граждан ${ }^{27}$. Кроме

25 См.: О профессиональных союзах, их правах и гарантиях деятельности: Федеральный закон от 12.01.1996 № 10-Ф3, С3 РФ. 15.01.1996, № 3, Ст. 148.

26 См.: О политических партиях: Федеральный закон от 11.07.2001 № 95-ФЗ, С3 РФ, 16.07.2001, № 29, Ст. 2950.

27 См. подробнее, в частности: О территориях опережающего социально-экономического развития в Российской Федерации: Федеральный закон от 29.12.2014 № 473-Ф3, СЗ РФ. 05.01.2015, № 1 (часть 1), Ст. 26. 
того, существование территории опережающего социально-экономического развития может быть в любой момент прекращено по решению Правительства Российской Федерации, если, например, в ходе мероприятий общественного контроля будет установлено, что этого требует необходимость охрани жизни и здоровья граждан, охрана окружающей среды, обеспечение обороны страны и безопасности государства и т.п.

Таким образом, федеральное, региональное и муниципальное законодательство образуют единое правовое поле, способствующее организации и осуществлению общественного контроля в различных областях государственного и муниципального управления, а также в части соблюдения прав, свобод и законных интересов граждан, а также их объединений.

Однако, на региональном и местном уровнях зачастую отсутствуют нормативно-правовые акты, регулирующие вопросы общественного контроля, а также посвящённые созданию и деятельности общественных палат низового уровня, что диктует необходимость их дальнейшего совершенствования.

\section{Резюме}

Полноценная реализация на практике конституционного принципа народовластия требует постоянного совершенствования института общественного контроля в Российской Федерации, выступающего, с одной стороны, в качестве гарантии реальности права народа на осуществление народовластия, а с другой стороны, механизма, препятствующего узурпации власти, ее незаконного присвоения, а также осуществления не в интересах граждан страны.

Система правового регулирования общественного контроля власти в России представлена несколькими группами нормативно-правовых актов национального законодательства. Настоящая статья посвящена исследованию федерального, регионального и муниципального законодательства в области регулирования общественного контроля в Российской Федерации.

В исследовании использовался ряд научных методов, в частности: сравнительноправовой; оценки; классификации.

В работе проведен сравнительный анализ нормативно-правовых актов, способствующих организации и функционированию системы общественного контроля в Российской Федерации, дана их авторская классификация.

Это позволило провести анализ нормативно-правовых основ механизма общественного контроля в Российской Федерации, определив их место, роль и значимость в организации системы общественного контроля в нашей стране. 
Vitaly Viktorovich Goncharov

\section{Features of Legal Regulation of Public Control in the Russian Federation at the Federal, Regional and Municipal Levels (Constitutional and Legal Analysis)}

Full implementation of the constitutional principle of democracy in practice requires continuous improvement of the institution of public control in the Russian Federation, acting, on the one hand, as a guarantee of the reality of the people's right to exercise democracy, and on the other hand, the mechanism that prevents the usurpation of power, its misappropriation, as well as the implementation is not in the interests of the citizens of the country.

The system of legal regulation of public control of power in Russia is represented by several groups of normative legal acts of national legislation. This article is devoted to the study of federal, regional and municipal legislation in the field of regulation of public control in the Russian Federation.

The study used a number of scientific methods, in particular: comparative legal; assessment; classification.

The paper presents a comparative analysis of legal acts that contribute to the organization and functioning of the system of public control in the Russian Federation, their author's classification.

This made it possible to analyze the regulatory framework of the public control mechanism in the Russian Federation, determining their place, role and importance in the organization of the public control system in our country.

KEY WORDS: federal, regional, municipal, legislation, public control, Russian Federation, constitutional and legal analysis, people, participation in the management of public affairs, power

\section{Библиография}

A. S. Bataev, Organization of Public Control in the Russian Federation at the Level of Municipalities (on the Example of the Southern and North Caucasus Federal Districts), Grozny 2018.

D. S. Mikheev, Ensuring Public Control is a Key Direction in the Development of the Principle of Publicity of Local Self-Government, «Lex Russica» 2015, V. 101, № 4.

T. N. Mikheeva, E.I. Belousov, Public Control at the Municipal Level: an Analysis of Legislation Novels, «Actual problems of economics and law» 2015, № 2.

O. V. Vorontsova, Public Environmental Control: Selected Issues of Judicial Practice, «Komi Bulletin of the Republican Academy of Public Administration and Management. Series: State and Law» 2016, № 21. 